\title{
The Potential Implications of Contemporary Use of Mobile I Tablet Devices in Street Photography, Especially for the Representation of People in the City
}

\author{
Dunmin SHI \\ Communication and Media School, University of Leeds, Leeds, UK
}

Email address:

me16d2s@leeds.ac.uk

To cite this article:

Dunmin SHI. The Potential Implications of Contemporary Use of Mobile / Tablet Devices in Street Photography, Especially for the Representation of People in the City. Humanities and Social Sciences. Vol. 5, No. 2, 2017, pp. 102-107. doi: 10.11648/j.hss.20170502.19

Received: March 31, 2017; Accepted: May 3, 2017; Published: May 10, 2017

\begin{abstract}
In present age, the appearance of mobile devices promoted the development of street photography, which enabled street photography represented more characteristics of the times. Firstly, mobile devices not only enriched the theme of street photography, but also made photography become more and more convenient and easy to operate so that enabled more amateurs to participate in street photography. Secondly, mobile devices also made photographs more authentic and with wide range of view point. Moreover, the mobile applications and social internet also contribute to communicate photographs, which provided more possibilities for people to share their viewpoint based on photographs. Finally, the appearance of mobile devices also resulted in some negative implications for both photography and society including photography authenticity and privacy issues especially in this media age.
\end{abstract}

Keywords: Street Photography, Mobile Photography, Internet Media

\section{Introduction}

Street photography developed with urbanization and it developed since the late 1880 s because of portable camera. [4] So street photographs became significant witness of urbanization. In this context, city landscape as well as people in the city became the crucial content of street photography from beginning to the end. Gradually, street photography is becoming not only to record the street scene, but also a significant way to concern about individuals and society. Besides, the development of photographic techniques made a contribution to the creation of street photography especially the representation of people in the city throughout the development of street photography from many perspectives. And new equipment also brought some influences on both photography and society. Recent years, mobile devices became more and more popular. It brought street photography plenty of new meaning and also debate. Based on this background, this essay will mainly talk about three parts. Firstly, it will introduce the historical background of street photography which contains the rise and development of cities, the changes of content of street photography as well as the improvement of photographic techniques. The second part of this essay is about the contribution of mobile devices to street photography, especially for representation of people in the city, which based on the characters of mobile devices. Finally, the third part is about the implications of mobile devices for both photography and society in the context of internet media age.

\section{Historical Context of "Street Photography"}

From the beginning of photography, street photography was considered as a significant type of photography. A large amount of photographers in different period keep exploring in this field. In the early stage of street photography, the street photographs expressed more about curiosity of the strange world. However, now with the development of industrialization and urbanization, street photography became an extremely powerful way to concern about individuals and society.

Jericho was the earliest city in the world which formed from 8000BC [5] whereas photography was born in 1839. [10] Compared with appearance of town, the cultural record of 
street was much later. From oral inheritance to literal communication and then to image communication showed the transition of media form from single communication media to combination of multiple media.

The birth of photography and the rise of street photography played a significant role in inheritance and development of street culture. Before photography was born in 1839, all record about street culture were based on words. When photography was born, bourgeois revolution in Europe had achieved success and industrial revolution started in $19^{\text {th }}$ century. The development of economy made the city which centered in politics and military gradually changed into centered in economy and people's life. [3] And this was the symbol of appearance of modern city. The birth of photography provided a powerful tool to record city landscape and citizen's life which changed dramatically in this period of time. Throughout history of photography, we can see that most of those photographs which indicated the characteristic of modern life in the process of industrialization and urbanization were from street photography. The photographers from different social hierarchy used their camera recorded their daily image fragments, which contributed to promote the social progress.

Street photography focus on contemporary daily life and cities, which uses fragmented images to express photographers' understanding about general characteristics of contemporary social life. Street photography also indicates photographers' identification and reflection about the city they live in. These kind of life scene are captured by camera and then become a part of our memory. Photography is an important method of life chronicle and social integration because photography is to record significant moments of life for people. [16] Pierre Bourdieu also think that cameras are expected to record some social occasions like family gatherings as well as holidays. [6] Except capturing these events, people who have cameras play social roles. [23]

Street photographs revealed essence of contemporary life and present texture of life. The characteristic of photography decides that photography record present life. And these kind of lens-based recording will become memory which related to visual context through time goes by. Over time, the value and significance these memories will be more prominent. [18] The history of contemporary society's development is the history of urbanization. [17] Photography was born in a special time, which developed simultaneously with urbanization. Because of photography, we can know the evolution history of human civilization and urbanization intuitively. Except for buildings, city landscapes are more about people who live in the city. Vivid daily life decides the richness of content of photographs. City life is the epitome of politics, economy and social life of the modern country. So city life is the creation source for street photographers.

The development of photographic techniques promotes the development of street photography. In the early stage of photography, photographers need to bring large format camera into street to finish their shot. And then $35 \mathrm{~mm}$ camera appeared which promoted the convenience of taking photographs. $35 \mathrm{~mm}$ rangefinder camera started to become popular to street photographer because it is very light, small and quiet. [12] however, at this time, photography is a kind of skill which only grasped by minority of people. In the year of 1888, George Eastman invented 'American Film' and one year after Kodak began to produce this kind of film. The invention of film improved the volume of photography equipment and simplified the operating procedure of photography. In 1891, Kodak began to produce the film that can be assembled by users themselves. Photography became an activity which everyone could take part in it. The tendency of Miniaturization of camera not only expanded the application fields of photography but also made photography could be used by ordinary families instead of only professions. It seems that the development of photographic technology promoted the mass amateur photography. [15] Besides, light-sensitive material also developed from daguerreotypes to wet plate, dry plate as well as negative and film. Shutter speed also shortened from a few minutes to several tenths of seconds or even milliseconds. [12] The increase of shutter speed provided more possibilities for photographers to concern about people and activities or other moving stuffs. We can see that in the early stage of street photography, most of photographs focused on buildings and city landscapes, however, large amounts of photographs about citizen's daily life came later. It is revealed that the development of street photography relied on the development of photographic techniques. The developmental level of photographic techniques decides the pervasiveness of street photography's form and theme. Street photography is a kind of visual adventure which represent the complicated relationship between photographer and subject, subject and city, photographer and city, subject and subject, photography and city.

\section{Contributions to the Representation of People of Using Mobile Devices}

In the mobile phone age, the appearance of cellphone provides street photography more possibilities. And camera phones make photographers produce some street photographs which represent the characters of internet age. Recent years, mobile phones increasingly become popular. The characters of camera phones make them contributes to street photography especially for representing people in the city from many perspectives.

Firstly, mobile phone is very small, convenient and portable. Compared to the digital camera, mobile devices which have cameras have an advantage in many aspects. 'The first keitai with a built-in digital camera was the PHS VP-210, marketed by Kyocera in July 1999.' [20] After that, mobile photography appeared.

Today, the mobile phone is a very portable device. At the background of internet, smartphone has become a part of our daily life. People use mobile phones to get information and communicate with each other. Precisely, it has become our necessities and a new way of communication, which means 
most people will take mobile phone at any time and in any where. So it may provide more possibilities to capture the scenes that happen accidently in people's daily life. Quickness is also a significant character of mobile phone. Using mobile phone to take photo is very quick. When people see something deserve to be concerned, they can take out their phone immediately and finish shot. Many fantastic characters appeared that people can not predict. So camera phone may be a good choice at this time. Furthermore, Mobile devices enable photographers to capture decisive moments easier. This suggests that the advantages of mobile devices in street photography compared with other big camera because of the quickness of taking photographs. On September $25^{\text {th }}$ of 2009 , the first iPhone photography collection The Best Camera Is The One That's With You was published by New Riders Press. The first day of sale on American Amazon broke a record of sale of all photography books. The name of this book may be a good annotation of mobile photography. Chase Jarvis said that for him, because he took his iPhone all the time, which enabled him never lose any sight of his daily life. [14]

Secondly, camera phone may contribute to capture the authenticity of people in the city. People will not be strong defensive when the photographers use the mobile phones to take street photographs since smart phones are highly acceptable in recent years. The development of technology only has meaning when they been used and absorbed in a new style. [7] In present age, camera phones gradually changed not only people's life style but also the way of communication. In this background, the mobile phone enriched the street photography and brought the new meaning of street photography. It seems easier to capture the authenticity of people in the city by using mobile devices. Because people may think mobile phone is not very aggressive compared with camera. When people use mobile devices to take photographs, they just need to look at the screen and press the button. The lens is at the back of the camera phone. Consequently, it is relatively difficult to distinguish whether people are taking photographs or texting messages. In many situations, people even don't notice that they are being filmed. Sometimes camera phones are also suitable for secret photography.

Thirdly, the smart phone enables photographer wide ranges of shot viewpoint, which make the characters in street photography become more abundant. 'In photography, viewpoint is regarded as one of crucial elements in art of photography, which related to the location as well as the point of view of photographs. [22] Viewpoint has great influence on quality of images. Different viewpoint could create different atmosphere and represent different characters of people. Viewpoint is related to lens, composition as well as the photographer's understanding of the photographed objects. Besides, viewpoint is the way how photographers observe the world. Equally important, viewpoint is also the way how photographers interpret the world. Viewpoint could also create the unique visual style of photographs. For example, from the documentary of Finding Vivian Maier [9], people can see the reason why Vivian Maier's photographs have very special visual effect is that she used twin-lens reflect camera and always put her camera on her chest. So the viewpoint of her photographs is always low angle. Many characters in her photographs look stalwart because of these reasons. Sometimes, one kind of visual style comes from the character of equipment. In other words, photographic technology is a part of photography culture which represented in the photographs. Similarly, mobile photographs also could display this character. Mobile phone's viewpoint is more flexible compared with camera. Traditional cameras use optical viewfinder to observe photographed objects which limited the photographer's viewpoint. However, the screen of mobile phone is live view, which provides photographers more possibilities to create. Because it is more easy to have low angle and depression angle by camera phones.

Fourthly, with the development of technology, the quality of mobile photographs is highly improved. And there are large amounts of applications for mobile phone to retouch the photographs which could make photographed object looks more beautiful. The technology of camera phones is highly improved which include pixel, photosensitivity as well as camera. And these improvements also offered more possibilities for photographers and changed their way of creation to some extent as well. For example, iPhone 7 improved its new camera systems and battery life, which through upgrade camera and add optical image stabilization, an $\mathrm{f} / 1.8$ aperture, as well as a six-element lens. These improvements promote the performance of camera phones in low light environment. [1] Another example is Huawei which cooperate with Leica to introduce a dual-lens, built-in dual-core ISP as well as professional DSP to Huawei P9. These improvements of smart phones enable mobile devices to improve their image focusing, shutter speeds and process speed. [13] The improvement of shutter and process speed provided photographers more possibilities to capture moving photographed object, which contribute to capture the people in the city. Because people in the street are always move. High shutter speeds could improve the definition of the photographed objects.

Besides, there are wide ranges of applications match up to the mobile phones which could make mobile photographs more attractive. Especially the mobile digital retouching applications for portrait are now becoming more and more popular. Large amounts of applications enrich the expression and entertainment of images. The combination of camera phones and retouching applications produce many dramatic photographs which show the character of mobile devices age. Finding interesting point is the way for people to understanding photographs. Interesting images seems more attractive and could stimulate thinking, which could boost expression effect of photographs. Mobile devices integrate shot, mobile digital retouching and social media. Recent years, Mobile digital retouch applications of portrait become more and more popular which satisfied people's aspiration of beauty. For example, MeituPic which is a very popular application in China, which provides professional filters, special effects as well as photography tools to enhance the expression of images especially for retouching people's face. [19] There are plenty 
of tools can make people's face looks more smooth and fair. These applications could create a kind of beauty which beyond real. And these effect may satisfy people's consumer psychology. Furthermore, these special effects also make

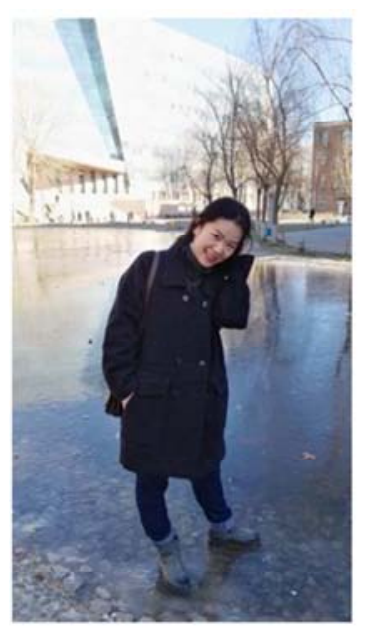

(1) Initial photo

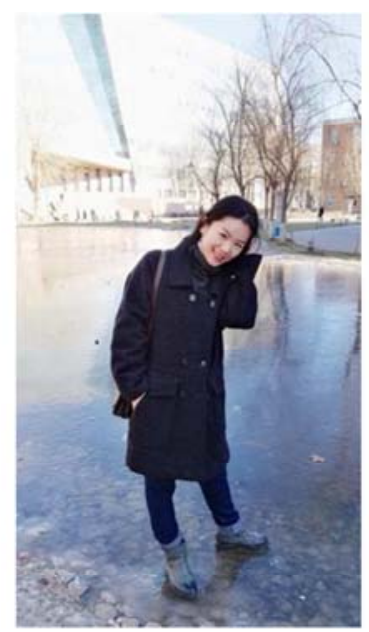

(2) post-processed photo

these portraits have their unique visual style and leave some marks of this cellphone age to these photographs. We can see from the pictures below.

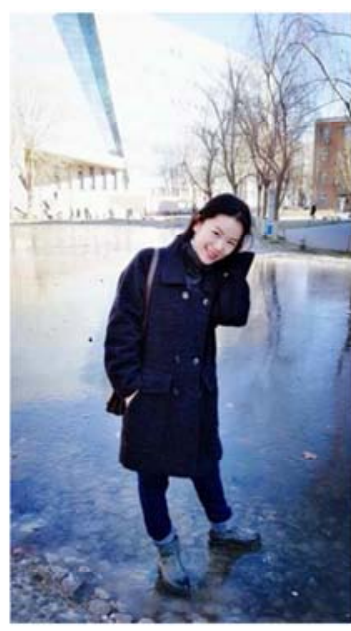

(3) photo with filter

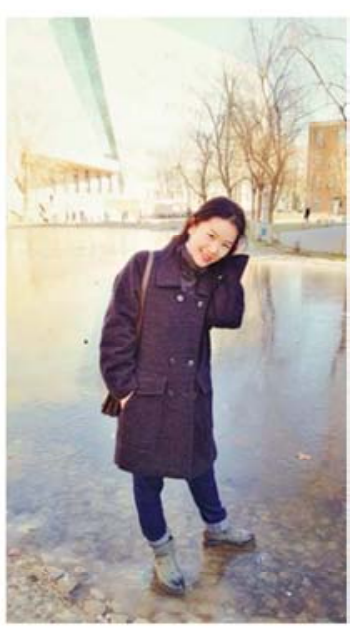

(4) changed color temperature

Figure 1. Demonstration of post-processing photograph by mobile applications.

At the same time, the new way of creation will influent people's aesthetic demand. However, heavily rely on special effect provided by applications make mobile photographs lack of authenticity.

Fifthly, mobile photographs of people could represent the characters of contemporary era. First of all, mobile phone is the product of modern science and technology which has the character of electronize and easy to operate. Secondly, the way of creation for mobile photography accord with the trend of modern art. In the classical age of Europe, visual art believes in realism. However, after $1880 \mathrm{~s}$, impressionism lead the mainstream of art from realism to expression. The visual artists tended to explore the inner world of people and the form of art became more diverse. Mobile photography could represent these changes of art concepts. Using mobile devices to represent people in the city could be an example to illustrate this point. Mobile photographs may have more subjectivities, which seems value subjective expression more than reality.

\section{Implications for Photography and Society}

In the present age, the popularity of mobile devices result in some potential implications for both photography and society. There are not only positive influences but also negative influences.

From the perspective of photography, firstly, almost everyone in this society have a mobile phone which means everyone has a possibility to become a photographer. Consequently, low production cost of mobile photographs lead to images overflow. As noted by Sontag Susan, 'Industrial societies turn their citizens into image-junkies.' [25] In our everyday life, people need to read plenty of images which been shot without deep thinking. There are large amounts of photographs of food and party and so on on social media website. It may suggest that people more value practicability than artistry of mobile photographs. For example, people may more concern about whether it is a beautiful picture rather than its profound meaning. Using mobile devices to take photographs sometimes is quicker than your brain. Sometimes, your fingers maybe have already pressed the button, when you haven't think how to shoot. The convenience and low cost of mobile photography sometimes make people forget that taking photographs need thinking. However, photographs which lack of thinking may can not avoid being discard. Although mobile devices have plenty of digital retouching applications. Furthermore, in the digital age, the photo is instant to see when photographers finish their shot, especially for mobile phone. So it results in decrease of the sense of expectation for photographs. In my view, this may be another reason for images overflow.

Secondly, wide ranges of photographers from different social background make the theme of street photography more diversity. Using mobile phones to take photographs is very easy to operate and mobile phone is very smart, which enable more people can take part in street photography. Not like the DSLR camera, many function of smart phone is artificial intelligence which lower the standard of photographer's skill requirement. Mobile devices promote the development of mass photography. On the one hand, the appearance of plenty of amateur also results in the decrease of quality of mobile photographs. On the other hand, the content of street photography also become more abundant.

From the perspective of society, firstly, using mobile devices even changed people's life style to some extent. Heavily rely on social media images may threatened people's life style. More and more people share their selfie, food and pets to the social media and long to look others' social media 
website. As noted by Sontag Susan, 'it is the most irresistible form of mental pollution.' [25] People seems long for beauty of the surface rather than the truth. Now people heavily rely on social media. The problem is that people who addicted in social media equate photographs with experience. In other words, they think shooting and reading photographs equals to take part in activities in their subconscious. According to Sontag Susan's point, 'needing to have reality confirmed and experience enhanced by photographs is an aesthetic consumerism to which everyone is now addicted.'[25] Once they don't have images, they will feel anxiety. However, the fact may not like that. So people addicted to photographs also affect their attendance of activities.

Secondly, camera phones contribute to the mobile communications as well as visual communications. Precisely, it is very easy to share mobile photographs in the social media. And images become more and more important in social communication in the present age. Furthermore, mobile devices also promote the efficiency of spread of photographs. The camera phones create a new model that is called 'aural-textual-visual communication' [23], which means that camera phones combined photographs, language and internet together. The camera phone not only integrate these different technologies but also introduce photography into oral and written language. [23] Because of the appearance of camera phone, photography is no longer camera-centred. A new type of photographic form appeared along with the changes of people's life style in the internet age. As a result, the increasing popularity of mobile phones with camera redefined and enriched the mobile communications as well as visual communications. [23] The camera phones also provided more possibilities for communication between people who come from different area with different values. Because the combination of mobile internet with image and text messages, people could upload their photographs to the social website within seconds after the images being taken. And people could get feedbacks from different people come from all of the world.

Thirdly, in the age of mobile photography, people may face a big challenge of protecting the right of privacy. Today, mobile devices make it easier to spread embarrassing and degrading photographs because people seems difficult to notice the mobile camera and it is very easy for people to upload these photographs to social website. Consequently, someone made proposals to ban the use camera phones to take photographs in public places. [23] And once the photographs are uploaded to the internet it is also difficult to control the spread of these images.

\section{Conclusion}

In conclusion, the characters of mobile devices promoted the development of street photography especially for expressing people in the city from many perspectives. First of all, mobile devices are very small, convenient and portable, which means photographers could take them all the time. And also because of the character of quickness, camera phones are very suitable for taking life scene that happen accidently. Secondly, mobile devices seem more possible to capture the authentic photographs of people in the city since they are not very aggressive compared with traditional camera which can be hide easily. Thirdly, mobile devices provide photographers more choices of viewpoint which could boost the expression of photographs. New technologies could change the way of creation for photography. Besides, there are plenty of applications that could match to the camera phones, which make portrait more beautiful. Camera phones not only give the meaning of new era to the street photography but also affect society. For example, camera phones integrated camera, retouching applications as well as internet, which may change people's life style and the way of communication. However, rely too much on mobile photographs may threaten people's attendance of activities. Furthermore, it seems that camera phones also bring a challenge of protecting the right of privacy. In a word, mobile photography may suggest that the development of technology will provide more possibilities for art creation.

\section{References}

[1] Apple. 2016. iPhone 7. [online] [Accessed 6 Dec. 2016]. Available from: http://www.apple.com/iphone-7/.

[2] Alper, M., 2013. War on Instagram: Framing conflict photojournalism with mobile photography apps. New Media \& Society, p.1461444813504265.

[3] Ashton, T. S., 1997. The industrial revolution 1760-1830. OUP Catalogue.

[4] Bate, D., 2016. Photography: the key concepts. Bloomsbury Publishing.

[5] Braidwood, R. J., 1957. Jericho and its setting in Near Eastern history. Antiquity, 31(122), pp.73-81.

[6] Bourdieu, P. and Whiteside, S., 1996. Photography: A middle-brow art. Stanford University Press.

[7] Deleuze, G., 1995. Negotiations, 1972-1990. Columbia University Press.

[8] Freeman, M., 2007. The Photographer's Eye: Composition and Design for Better Digital Photos. CRC Press.

[9] Finding Vivian Maier. 2014. [Film]. John Maloof and Charlie Siskel. Dir. USA.

[10] Gasser, M., 1992. Histories of photography 1839-1939. History of Photography, 16(1), pp.50-60.

[11] Gye, L., 2007. Picture this: The impact of mobile camera phones on personal photographic practices. Continuum: Journal of Media \& Cultural Studies, 21(2), pp.279-288.

[12] Goldberg, N., 1992. Camera technology: the dark side of the lens. Academic Press.

[13] Huawei, 2016. [online] [Accessed 6 Dec. 2016]. Available from:

http://consumer.huawei.com/en/mobile-phones/p9/index.html. 
[14] Jarvis, C., 2009. The Best Camera Is The One That's With You: iPhone Photography by Chase Jarvis. New Riders.

[15] Jenkins, R. V., 1975. Technology and the market: George Eastman and the origins of mass amateur photography. Technology and Culture, 16(1), pp.1-19.

[16] Keightley, E. and Pickering, M., 2006. For the record popular music and photography as technologies of memory. European journal of cultural studies, 9(2), pp.149-165.

[17] Knox, P. L. and McCarthy, L., 2012. Urbanization: An introduction to urban geography. Boston: Pearson.

[18] Lury, C., 1998. Prosthetic culture: Photography, memory and identity. Psychology Press.

[19] Meitu, (2016). [online]. [Accessed 6 Dec. 2016]. Available at: http://global.meitu.com/en/products/.

[20] Okada, T., 2005. Youth culture and the shaping of Japanese mobile media: Personalization and the keitai Internet as multimedia. Personal, portable, pedestrian: Mobile phones in Japanese life, pp.41-60.

[21] Villi, M., 2015. "Hey, I'm here Right Now": Camera phone photographs and mediated presence. Photographies, 8(1), pp.3-22.

[22] Rawat, Y. and Kankanhalli, M., 2016. ClickSmart: A Context-Aware Viewpoint Recommendation System for Mobile Photography.

[23] Rubinstein, D., 2005. Cellphone photography; The death of the camera and the arrival of visible speech. The Issues in Contemporary Culture and Aesthetics, 1, pp.113-118.

[24] Sontag, S., 1977. On photography. Macmillan.

[25] Yin, W., Mei, T., Chen, C.W. and Li, S., 2014. Socialized mobile photography: Learning to photograph with social context via mobile devices. IEEE Transactions on Multimedia, 16(1), pp.184-200. 